\title{
Measuring volume kinetics of human monocytes in response to cryoprotectants using microfluidic technologies
}

Raju, Rekha; Hohn, Hannes; Karnutsch, Christian; Khoshmanesh, Khashayar; Bryant, Gary https://researchrepository.rmit.edu.au/esploro/outputs/9921860733001341/filesAndLinks?institution=61RMIT_INST\&index=null

Raju, R., Hohn, H., Karnutsch, C., Khoshmanesh, K., \& Bryant, G. (2019). Measuring volume kinetics of human monocytes in response to cryoprotectants using microfluidic technologies. Applied Physics Letters, 114(22), 1-4. https://doi.org/10.1063/1.5096199

Document Version: Published Version

Published Version: https://doi.org/10.1063/1.5096199

Repository homepage: https://researchrepository.rmit.edu.au (c) 2019 Author(s). Published under license by AIP Publishing.

Downloaded On 2023/04/26 23:14:50 +1000 


\title{
Measuring volume kinetics of human monocytes in response to cryoprotectants using microfluidic technologies
}

Cite as: Appl. Phys. Lett. 114, 223702 (2019); doi: 10.1063/1.5096199

Submitted: 14 March 2019 • Accepted: 21 May 2019.

Published Online: 7 June 2019

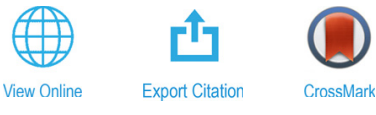

Rekha Raju, (iD Hannes Höhn, ${ }^{2,3}$ Christian Karnutsch, ${ }^{2}$ Khashayar Khoshmanesh, ${ }^{3, a)}$ (iD) and Gary Bryant ${ }^{7}$

\section{AFFILIATIONS}

${ }^{1}$ Centre for Molecular and Nanoscale Physics, School of Science, RMIT University, Melbourne, Victoria 3001, Australia

${ }^{2}$ Institute for Sensor- and Information Systems (ISIS), Research Group "Integrated Optofluidics and Nanophotonics (IONAS),"

University of Applied Sciences Karlsruhe, Karlsruhe 76133, Germany

${ }^{3}$ School of Engineering, RMIT University, Melbourne, Victoria 3001, Australia

${ }^{a)}$ Author to whom correspondence should be addressed: khashayar.khoshmanesh@rmit.edu.au

\begin{abstract}
Cryopreservation is a common strategy for the preservation of biological cells and tissues. While conventional platforms such as cell culture well plate systems enable measuring cell responses to various cryoprotectants, the drawbacks associated with capturing and imaging of cells limit the utility of such systems. Microfluidic technologies facilitate the capturing, chemical stimulation, and imaging of cells using low sample volumes. Here, we utilized microfluidic technologies for the hydrodynamic capturing of single human monocytes and studying the cell volume kinetics in response to a cryoprotectant in real time. Our approach facilitates conducting multistep cellular assays, especially for studying individual cell osmotic response and determining cell membrane permeability to cryoprotectants.
\end{abstract}

Published under license by AIP Publishing. https://doi.org/10.1063/1.5096199

Cryopreservation, the storage of samples in liquid nitrogen $\left(-196^{\circ} \mathrm{C}\right)$, is generally used for preservation of cells and tissues. ${ }^{1-4}$ Cryopreservation protocols rely on the penetration of cryoprotective agents (CPAs) to the cell to reduce the damage induced by the freezing process. In this regard, studying the biophysical response of cells to CPAs and especially the cell permeability is an important step in the development of "cell specific" cryopreservation protocols.

When cells are exposed to a hypertonic solution of permeable solutes such as CPAs, the osmotic gradient across the cell membrane leads to the efflux of water, resulting in the initial "shrinkage" of the cells. The penetration of CPA into the cell reverses the osmotic gradient causing the influx of water, enabling the cell to "swell" back to approximately its initial volume. ${ }^{6,7}$ Thus, the total cell response to permeable CPAs can be described as a "shrink-swell behavior." Membrane permeability can be calculated from this volume response using the Kedem-Katchalsky two-parameter transport equations. ${ }^{8-11}$

Several methods have been used to quantify the permeability of cells based on their volume changes. These include the use of differential scanning calorimetry, ${ }^{12}$ electronic particle counters, ${ }^{13}$ stoppedflow light scattering, ${ }^{14,15}$ and micropipette perfusion. ${ }^{16,17}$ However, problems associated with the capture of cells, ambiguity of images, exchange of solutions, and requirement of a large volume of cell sample might limit the application of these methods.

Microfluidic technologies address these limitations, as they enable the user to: (i) confine cells within a chamber/trap, preventing imaging ambiguity due to overlapping of cells or their movement out of the focus plane, (ii) monitor the changes of cellular conditions following the perfusion of various isotonic and nonisotonic media, (iii) analyze cell kinetics over extended periods without any dislodgement, thus allowing for better image acquisition, and (iv) use low cell numbers and reagent volumes. ${ }^{18-25}$ Due to these unique features, microfluidic systems have been used for investigating cell membrane transport properties such as permeability to water and CPAs. ${ }^{6,26-29}$

In the present study, we utilized microfluidic technology for hydrodynamic capturing of single human monocytes (THP-1 cells) and analyzing their volumetric response to CPAs in real-time.

We utilized cup-shaped ${ }^{21}$ and serpentine-shaped ${ }^{19}$ microfluidic cell traps and compared their suitability for measuring the volumetric response of THP-1 cells to CPAs. These microfluidic structures were fabricated by direct laser writing using two-photon polymerization ${ }^{30}$ and replicated in poly-dimethylsiloxane (PDMS) using soft lithogra$\mathrm{phy}^{31}$ techniques. Direct laser writing facilitated the rapid prototyping 
of microfluidic structures with aspect ratios of $\sim 9$, which is rather challenging using conventional lithography techniques. ${ }^{32}$ The fabrication involved design, preparation, laser writing, developing, replicating, and assembly, as described in supplementary material S1, and is schematically shown in Fig. 1.

Figure 2 presents the experimental procedure, which can be divided into five steps, including channel filling, cell loading, cell stabilization, cell shrinking, and cell swelling, as described below.

Channel filling: This involved applying 70\% ethanol solution for degassing followed by applying phosphate buffered saline (PBS) and

(a)

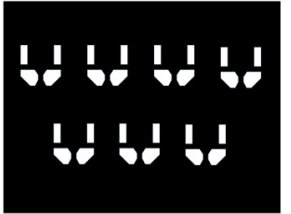

Step 1: Design of negative mask

(b)

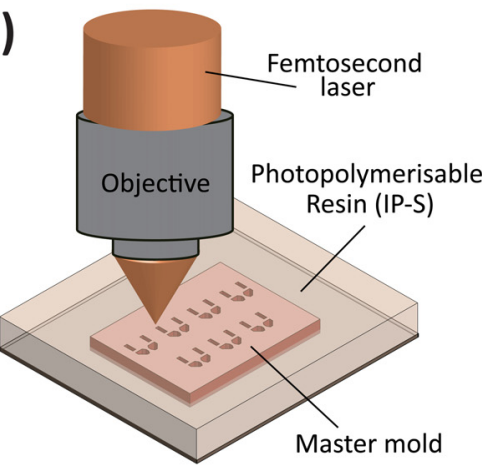

Step 2: Fabrication of master mold

(c)

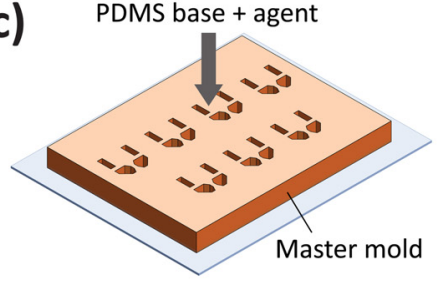

Step 3: Pouring of uncured PDMS onto the master mold

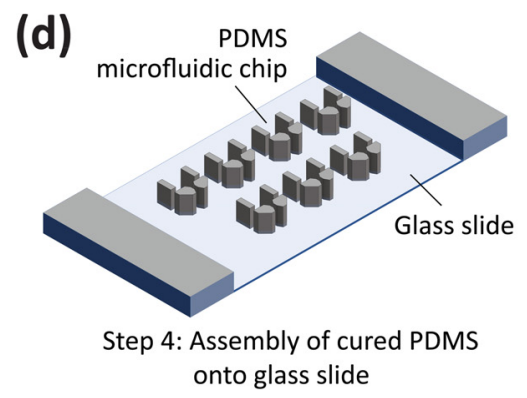

FIG. 1. Fabrication process of the microfluidic traps combining direct laser writing and soft lithography techniques.
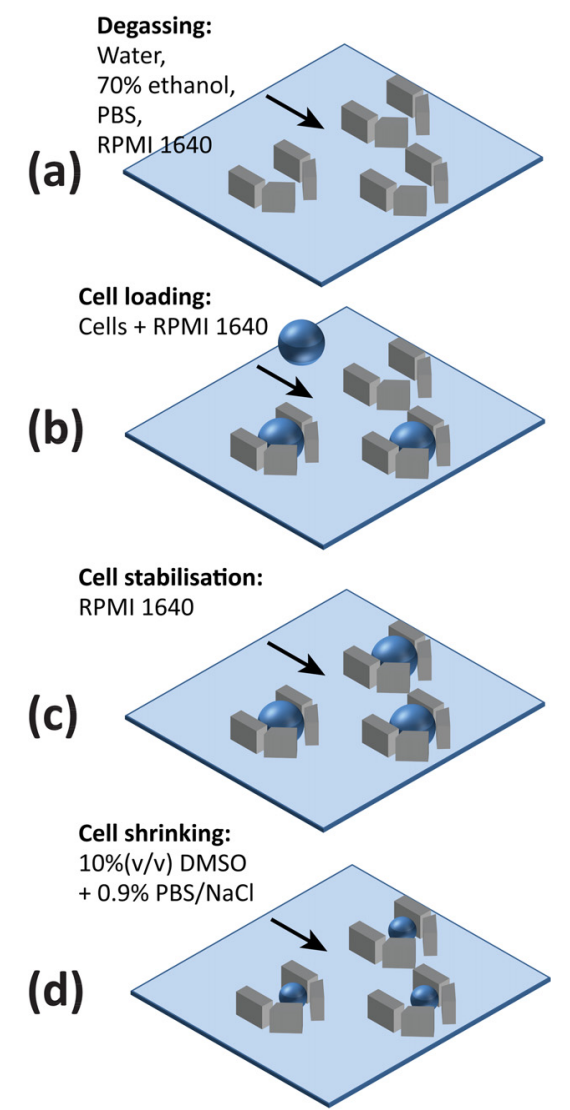

Cell swelling:

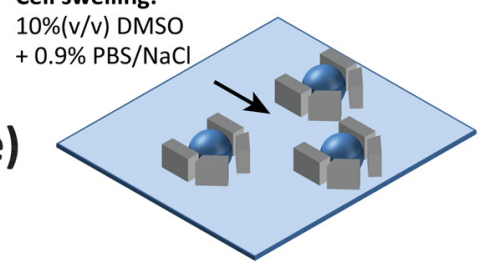

FIG. 2. Studying the shrink-swell behavior of cells in response to permeable CPA (DMSO) perfusion using a cup-shaped trap microfluidic device: (a) degassing and channel filling, (b) cell loading, (c) cell stabilization, (d) cell shrinking following the application of hypertonic DMSO, and (e) cell swelling due to the DMSO penetration and subsequent water influx into the cell.

RPMI1640 cell culture medium to fill the channel [Fig. 2(a)]. These solutions were added into the inlet reservoir and withdrawn through the outlet port using a syringe pump (PHD 2000 Infusion, Harvard Apparatus).

Cell loading: This involved applying an aliquot of cell suspension ( $\sim 30-50 \mu \mathrm{l}, \sim 2.5 \times 10^{5} \mathrm{cells} / \mathrm{ml}$ ) to the channel to facilitate hydrodynamic capturing of cells [Fig. 2(b)]. Further details on THP-1 cells can be found in supplementary material S2.

Cell stabilization: This involved the withdrawal of RPMI1640 for at least $30 \mathrm{~s}$ to enable cell equilibrium [Fig. 2(c)].

Cell shrinking: This involved applying a hypertonic solution of a permeable CPA [dimethyl sulfoxide (DMSO)]. The higher extracellular osmolality of CPA led to the efflux of intracellular water, resulting in the shrinkage of the cells [Fig. 2(d)]. 
Cell swelling: The constant water loss along with the constant influx of CPA due to the concentration gradient across the cell membrane reversed the osmotic gradient across the cell membrane just after the cells experienced the maximum shrinkage. The reversed osmotic gradient led to an influx of water into the cells, causing the swelling of cells [Fig. 2(e)].

Figure 3 presents the cryoprotectant permeability measurement of human monocyte cells using cup-shaped traps. This design incorporated an array of 17 independent traps [Fig. 3(a)]. Each trap had a width of $25 \mu \mathrm{m}$ and a height of $35 \mu \mathrm{m}$ in order to capture and retain individual THP-1 cells. Each trap consisted of four elements isolated with a gap of $4 \mu \mathrm{m}$ to minimize the pressure drop and maximize the chance of hydrodynamic trapping of cells. This gap was set to $4 \mu \mathrm{m}$ to ensure that the cells would not squeeze through them and escape from the traps.

This allowed us to capture single THP-1 cells and monitor their dynamic volume changes in response to $10 \%(\mathrm{v} / \mathrm{v})$ DMSO in real-time [Fig. 3(b)], based on which we obtained the average volume kinetics of multiple captured cells [Fig. 3(c)]. Numerical simulations revealed that the concentration of CPA solution in the first few seconds of perfusion and the hydrodynamic pressure are higher at the front side of the trapped cells due to the direction of flow (supplementary material S3), with both parameters affecting the osmotic gradient across the cell membrane.

Images were captured using an inverted microscope (Olympus IX71 inverted optical microscope) equipped with a CCD camera at a
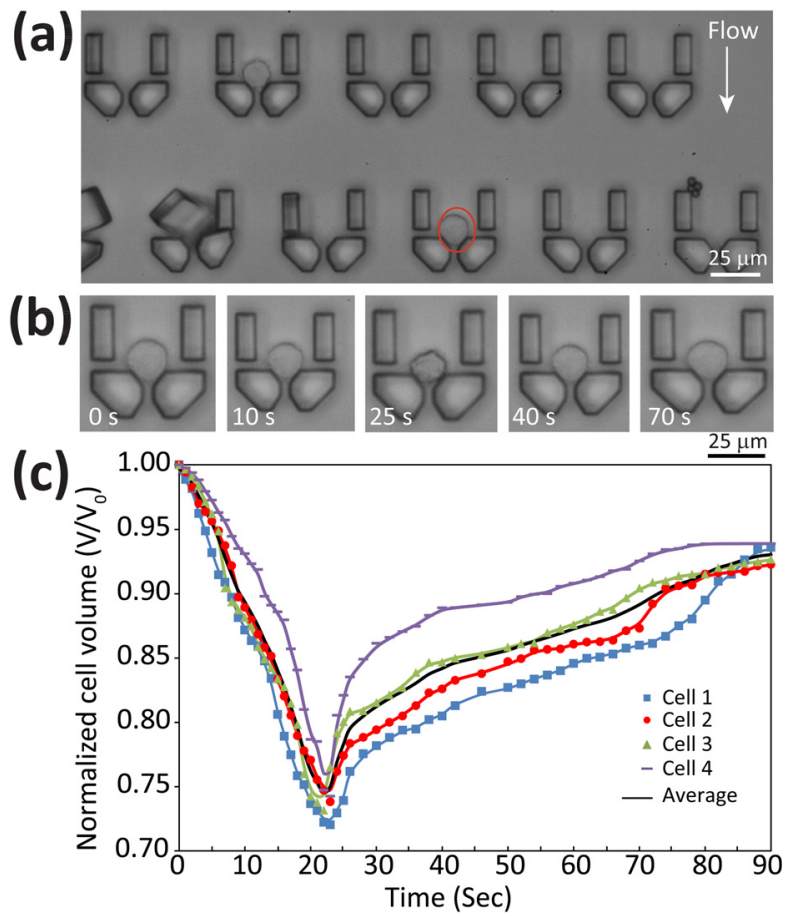

FIG. 3. THP-1 cell volume kinetics using the cup-shaped cell trap in response to hypertonic CPA solution $10 \%$ (v/v) DMSO in $0.9 \%$ PBS/NaCl: (a) cup-shaped cell traps, (b) time-lapse images showing the volume changes of a representative THP1 cell, and (c) volume kinetics of four THP-1 cells captured with the average shown as a black curve. resolution of $1024 \times 1024$ and a CMOS sensor (Mikrotron MC1362). For this camera $(14 \mu \mathrm{m} /$ pixel on CCD, $10 \times$ magnification, $1 \times 1$ binning), the pixel size was obtained as image pixel size $=$ camera pixel size $\times$ binning/magnification $=1.4 \mu \mathrm{m}$, which was sufficient for monitoring the THP- 1 cells with a diameter range of $15 \pm 3 \mu \mathrm{m}$ (average \pm standard deviation). Images were processed using Image (https:// imagej.nih.gov/ij/). Given the nonuniformity of the osmotic gradient across the cell membrane, the area of trapped cells was measured using the "freehand selections/measure" tabs of ImageJ, based on which the equivalent radius and volume of the cells were calculated.

Our results indicated the instantaneous shrinkage of captured cells due to water efflux in response to the osmotic gradient across the cell membrane. The minimum cell volume was obtained as $73.3 \%$ $\pm 0.99 \%$ of the isotonic initial volume, which occurred at $23 \pm 1 \mathrm{~s}$. Next, the cells began to swell as DMSO diffused into the cells. During this "swelling" phase, water also reenters the cells driven by the osmotic pressure gradient generated by DMSO.

Figure 4 presents the results obtained by the serpentine-shaped cell traps. Each trap had a width of $25 \mu \mathrm{m}$ and a height of $30 \mu \mathrm{m}$ with a gap of $4 \mu \mathrm{m}$ at the downstream of each trap [Fig. 4(a)]. Similar shrink-swell behavior was obtained [Fig. 4(b)]. The minimum cell volume was obtained as $68.4 \% \pm 2.8 \%$ of the isotonic initial volume, which occurred at $28 \pm 1$ s [Fig. 4(c)]. Compared to the cup-shaped traps, the minimum cell volume increased by $\sim 5 \%$ and delayed by $\sim 5 \mathrm{~s}$. This is attributed to the localized deformation of the cells at their backside facing the $4 \mu \mathrm{m}$ gap that significantly reduced the sphericity
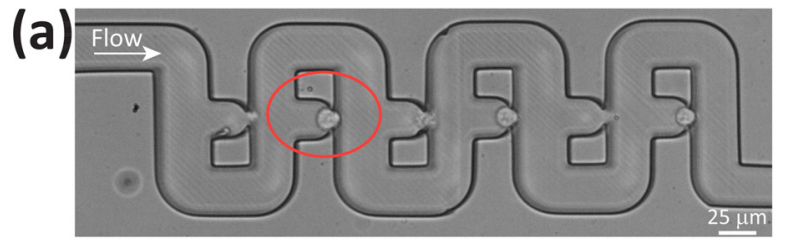

(b)

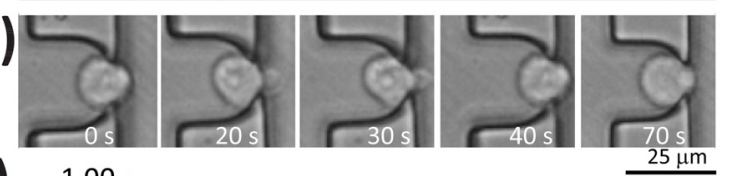

(c)

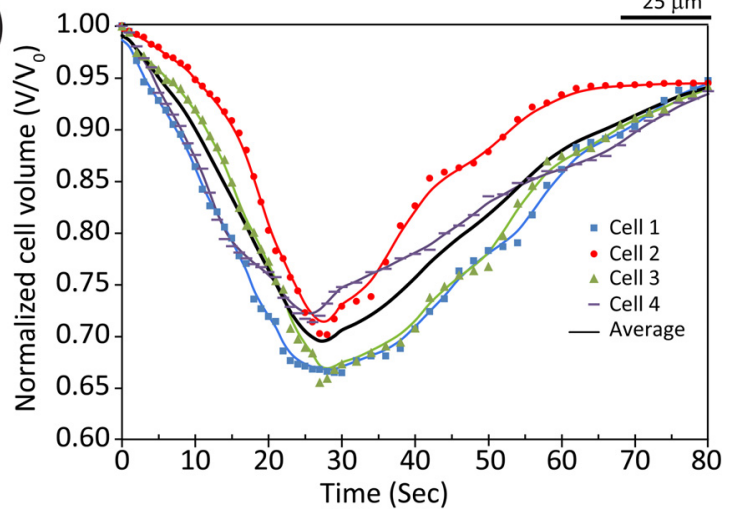

FIG. 4. THP-1 cell volume kinetics using the serpentine-shaped cell trap in response to $10 \%$ (v/v) DMSO in $0.9 \% \mathrm{PBS} / \mathrm{NaCl}$ : (a) serpentine-shaped cell traps, (b) time-lapse images showing the volume changes of a representative THP-1 cell, and (c) volume kinetics of four THP-1 cells captured with the average shown as a black curve. 
of the cell. Our experiments showed the superiority of cup-shaped traps for (i) studying the shrink-swell behavior of cells due to a higher number of captured cells per each channel ( $8_{\text {cup }}$ vs $\left.4_{\text {serpentinne }}\right)$ and (ii) maintaining the cell sphericity ( $0.913_{\text {cup }}$ vs $\left.0.822_{\text {serpentinne }}\right)$ during the cell shrinkage.

In summary, we investigated the volume kinetics (shrink-swell behavior) of THP-1 cells in response to a CPA (DMSO) using microfluidic technologies. Compared to existing technologies, our method facilitated (i) rapid capturing of single cells without secondary mechanisms such as surface functionalization, (ii) providing desired osmotic gradients across the cell membrane by perfusing cryoprotective agents, and (iii) real-time imaging of cells during the shrinkage and swelling phases due to their stability. Future work includes developing microfluidic systems with multiple trapping arrays to enable parallel studying of cell volume kinetics to various CPAs and developing more sophisticated microfluidic platforms capable of conducting multistep cellular assays, paving the way for discovering CPAs.

See the supplementary material for S1: Fabrication details, S2: Cell preparation process, and S3: Numerical simulations.

The authors wish to acknowledge RMIT's MicroNano Research Facility (MNRF) for fabrication of microfluidic devices. R.R. acknowledges the Australian Government Research Training Program Scholarship. H.H. acknowledges funding from The AustralianGerman Study Centre for Optofluidics and Nanophotonics (SCON) for visiting RMIT University.

K.K. acknowledges the Australian Research Council for the Discovery Grant (No. DP180102049). G.B. acknowledges funding from the Australian Research Council under Linkage Grant (Nos. LP140100993 and LP160101496).

\section{REFERENCES}

'B. M. Reed, Plant Cryopreservation: A Practical Guide (Springer, New York, 2008).

${ }^{2}$ A. Kaczmarczyk, V.-M. Rokka, and E. J. Keller, Potato Res. 54(1), 45-79 (2011).

${ }^{3}$ A. Kaczmarczyk, B. Funnekotter, S. R. Turner, E. Bunn, G. Bryant, T. E. Hunt, and R. L. Mancera, Cryoletters 34(5), 508-519 (2013).

${ }^{4}$ J. R. Youn and Y. S. Song, Appl. Phys. Lett. 101(13), 133701 (2012).

${ }^{5}$ Y. Zheng, G. Zhao, Y. Zhang, and R. Gao, Sens. Actuators, B: Chem. 255, 647-656 (2018).
${ }^{6}$ L. Weng, F. Ellett, J. Edd, K. H. Wong, K. Uygun, D. Irimia, S. L. Stott, and M. Toner, Lab Chip 17(23), 4077-4088 (2017).

${ }^{7}$ J. O. M. Karlsson and M. Toner, in Principles of Tissue Engineering, 2nd ed., edited by R. Langer and J. Vacanti (Academic Press, San Diego, 2000), pp. 293-307.

${ }^{8}$ P. Mazur, J. Gen. Physiol. 47(2), 347-369 (1963).

${ }^{9}$ P. Mazur, Am. J. Physiol.-Cell Physiol. 247(3), C125-C142 (1984).

${ }^{10} \mathrm{P}$. Mazur, Science 168(3934), 939-949 (1970).

"O. Kedem and A. Katchalsky, Biochim. Biophys. Acta 27, 229-246 (1958).

${ }^{12}$ R. V. Devireddy, D. Raha, and J. C. Bischof, Cryobiology 36(2), 124-155 (1998).

${ }^{13}$ J. Gilmore, L. McGann, J. Liu, D. Gao, A. Peter, F. Kleinhans, and J. Critser, Biol. Reprod. 53(5), 985-995 (1995).

${ }^{14}$ A. Verkman and H. E. Ives, Am. J. Physiol. -Renal Physiol. 250(4), F633-F643 (1986).

${ }^{15}$ H. J. Worman, T. A. Brasitus, P. K. Dudeja, H. A. Fozzard, and M. Field, Biochemistry 25(7), 1549-1555 (1986).

${ }^{16}$ D. Gao, J. McGrath, J. Tao, C. Benson, E. Critser, and J. Critser, J. Rerprod. Fertil. 102(2), 385-392 (1994).

${ }^{17}$ L. De Santis, G. Coticchio, S. Paynter, D. Albertini, K. Hutt, I. Cino, M. Iaccarino, A. Gambardella, C. Flamigni, and A. Borini, Hum. Reprod. 22(10), 2776-2783 (2007).

${ }^{18}$ D. Di Carlo, N. Aghdam, and L. P. Lee, Anal. Chem. 78(14), 4925-4930 (2006).

${ }^{19}$ W.-H. Tan and S. Takeuchi, Proc. Natl. Acad. Sci. U. S. A. 104(4), 1146-1151 (2007).

${ }^{20}$ A. M. Skelley, O. Kirak, H. Suh, R. Jaenisch, and J. Voldman, Nat. Methods 6(2), 147-152 (2009).

${ }^{21}$ D. Wlodkowic, S. Faley, M. Zagnoni, J. P. Wikswo, and J. M. Cooper, Anal. Chem. 81(13), 5517-5523 (2009).

${ }^{22}$ T. D. Nguyen, V. T. Tran, Y. Q. Fu, and H. Du, Appl. Phys. Lett. 112(21), 213507 (2018).

${ }^{23}$ C. B. Zhang, W. Gao, Y. J. Zhao, and Y. P. Chen, Appl. Phys. Lett. 113(20), 203702 (2018).

${ }^{24}$ D. Wlodkowic, K. Khoshmanesh, J. C. Sharpe, Z. Darzynkiewicz, and J. M. Cooper, Anal. Chem. 83(17), 6439-6446 (2011).

${ }^{25}$ S. Baratchi, F. J. Tovar-Lopez, K. Khoshmanesh, M. S. Grace, W. Darby, J. Almazi, A. Mitchell, and P. McIntyre, Biomicrofluidics 8(4), 044117 (2014).

${ }^{26}$ H. H. Chen, J. J. Purtteman, S. Heimfeld, A. Folch, and D. Gao, Cryobiology 55(3), 200-209 (2007).

${ }^{27}$ C. Fang, F. Ji, Z. Shu, and D. Gao, Lab Chip 17(5), 951-960 (2017).

${ }^{28}$ G. Zhao, Z. Zhang, Y. Zhang, Z. Chen, D. Niu, Y. Cao, and X. He, Lab Chip 17(7), 1297-1305 (2017).

${ }^{29} \mathrm{G}$. Zhao and J. Fu, Biotechnol. Adv. 35(2), 323-336 (2017).

${ }^{30}$ A. Selimis, V. Mironov, and M. Farsari, Microelectron. Eng. 132, 83-89 (2015).

${ }^{31}$ D. Qin, Y. Xia, and G. M. Whitesides, Nat. Protocols 5(3), 491-502 (2010).

${ }^{32}$ A. del Campo and E. Arzt, Chem. Rev. 108(3), 911-945 (2008). 